\title{
Knockdown of CAVEOLIN-1 Sensitizes Human Basal-Like Triple-Negative Breast Cancer Cells to Radiation
}

\author{
Man Zou ${ }^{a}$ Yanhui Lib Shu Xia ${ }^{a}$ Qian Chu ${ }^{a}$ Xiaoguang Xiao ${ }^{a}$ Hong Qiu ${ }^{a}$ \\ Yu Chen ${ }^{a}$ Zu'an Zheng $^{a} \quad$ Fei Liu ${ }^{a} \quad$ Liang Zhuang $^{a}$ Shiying Yu ${ }^{a}$
}

a'Department of Oncology, Tongji Hospital, Tongji Medical College, Huazhong University of Science and Technology, Wuhan, bDepartment of Cardiology, Tongji Hospital, Tongji Medical College, Huazhong University of Science and Technology, Wuhan, P.R. China

\section{Key Words}

Caveolin-1 - SiRNA - Radiosensitization - DNA damage and repair - Basal-like triple negative breast cancer

\begin{abstract}
Background/Aims: Triple-negative breast cancer (TNBC) is a high-risk breast cancer phenotype without specific targeted therapy options and is significantly associated with increased local recurrence in patients treated with radiotherapy. CAVEOLIN-1 (CAV-1)-mediated epidermal growth factor receptor (EGFR) nuclear translocation following irradiation promotes DNA repair and thus induces radiation resistance. In this study, we aimed to determine whether knockdown of CAV-1 enhances the radiosensitivity of basal-like TNBC cell lines and to explore the possible mechanisms. Methods: Western blotting was used to compare protein expression in a panel of breast cancer cell lines. Nuclear accumulation of EGFR as well as DNA repair and damage at multiple time points following irradiation with or without CAV-1 siRNA pretreatment were investigated using western blotting and confocal microscopy. The radiosensitizing effect of $C A V-1$ siRNA was evaluated using a clonogenic assay. Flowcytometry was performed to analyse cell apoptosis and cell cycle alteration. Results: We found that CAV1 is over-expressed in basal-like TNBC cell lines and barely expressed in HER-2-positive cells; additionally, we observed that HER-2-positive cell lines are more sensitive to irradiation than basal-like TNBC cells. Our findings revealed that radiation-induced EGFR nuclear translocation was impaired by knockdown of CAV-1. In parallel, radiation-induced elevation of DNA repair proteins was also hampered by pretreatment with $C A V-1$ siRNA before irradiation. Silencing of $C A V-1$ also promoted DNA damage $24 \mathrm{~h}$ after irradiation. Colony formation assays verified that cells could be radiosensitized after knockdown of $C A V-1$. Furthermore, $G_{2} / M$ cell cycle arrest and apoptosis enhancement may also contribute to the radiosensitizing effect of $C A V$ 1 siRNA. Conclusion: Our results support the hypothesis that CAV-1 knockdown by siRNA causes increased radiosensitivity in basal-like TNBC cells. The mechanisms associated with this effect are reduced DNA repair through delayed CAV-1-associated EGFR nuclear accumulation and induction of $G_{2} / M$ arrest and apoptosis through the combined effects of CAV-1 siRNA and radiation.




\section{Cellular Physiology Cell Physiol Biochem 2017;44:778-791 \begin{tabular}{l|l|l} 
and Biochemistry Publisned onIIne: November 23, 2017 & $\begin{array}{l}\text { (c) } 2017 \text { The Author(s). Published by S. Karger AG, Basel } \\
\text { www.karger.com/cpb }\end{array}$ \\
\hline
\end{tabular} \\ Zou et al.: Knockdown of CAVEOLIN-1 Increases Radiosensitivity in TNBC Cells}

\section{Introduction}

Breast cancer is one of the most common malignant diseases and a major cause of death among women worldwide [1]. It is widely recognized that breast cancer is a heterogeneous disease with subtypes that express various molecular biomarkers and are diverse in their biological behaviour and response to therapy [2]. Gene microarray profiling of human breast carcinomas has led to categorization of invasive breast carcinomas into five distinct subtypes: luminal A (ER+, PR+, HER-2-), luminal B (ER+, PR+, HER-2+), normal breast-like, HER-2 over-expressing, and basal-like breast cancer (BLBC) [2]. The BLBC subtype, which accounts for $15 \%$ of breast cancers, is associated with the most aggressive behaviour and poor survival and often lacks ER, PR, and HER-2 expression but expresses one or more of the specific basal markers CK5, CK14, CK17, and epidermal growth factor receptor (EGFR) [3].

Radiotherapy is widely used to treat cancer patients because of its ability to create DNA damage and induce apoptosis in a variety of cancer types [4, 5]. Because efficient targeted treatments for basal-like triple-negative breast cancer (TNBC) phenotype are scarce, radiotherapy is often used as adjuvant therapy for basal-like TNBC patients, although radiotherapy has not consistently led to a gain in overall survival [6-8]. Evidence to explain the factors governing radioresistance in basal-like TNBC patients who develop local recurrence and distant metastasis is still unclear. Aberrant expression or activity of EGFR has been strongly linked to the pathogenesis of many human tumours $[9,10]$. It was demonstrated that unlike EGF treatment that induced endocytosis and subsequent lysosomal degradation of EGFR, unspecific stimuli such as UV-radiation, oxidative stress and radiation could induce EGFR nuclear accumulation [11-14]. Emerging evidence indicates that nuclear EGFR promotes DNA repair by interacting with DNA-dependent protein kinase (DNA-PK) $[15,16]$. Most recently, the ability of nuclear EGFR to modulate chromatin access upon radiation treatment suggests that nuclear EGFR enhances resistance to radiation [17]. Blockage of nuclear EGFR transport by cetuximab decreased DNA-PK activity and consequently increased residual DNA damage and reduced survival after radiation treatment [18]. These observations demonstrate a crucial role of nuclear EGFR in regulation of nonhomologous end-joining (NHEJ) DNA repair following DNA damage events and suggest a potential therapeutic target for cancer treatment.

CAVEOLIN-1 (CAV-1), which is the principal structural protein of caveolae, plays a pivotal role in signalling transduction and intracellular trafficking of cellular components [19-21]. Khan et al. reported that exposure to oxidative stress can lead to CAV-1-dependent perinuclear accumulation of EGFR [13]. It was also demonstrated that, in A549 cells, radiationinduced EGFR internalization is associated with CAV-1 [14]. Blocking src signalling with PP2 led to decreased phosphorylation of CAV-1 at Y14 and prevented radiation-induced EGFR transport into the nucleus [14]. In pancreatic cell lines, knockdown of $C A V-1$ sensitized tumour cells to ionizing radiation [22]. The role of CAV-1 in cancer development and progression is contentious and varies with tumour type. CAV-1 was initially reported to have tumour suppressive properties in rectal cancer, glioblastoma and breast cancer [23-25]. By contrast, there are several lines of evidence to suggest that CAV-1 may have oncogenic properties in colon cancer, lung cancer, prostate cancer and hepatocellular cancer [26-29]. Some studies reported that CAV-1 is a marker of myoepithelial cells because it is over-expressed and amplified in BLBC subtype human tissue samples [30, 31]. These findings contradicted those indicating that $C A V-1$ is a cancer suppressing gene that is often lost in breast cancer, leading to tumour growth and metastasis [25]. Because the function of CAV-1 in basal-like TNBC cells is not fully understood, in the present study, we focused on evaluating whether high expression of CAV-1 in basal-like TNBC cell lines is correlated with radioresistance and endeavoured to discover a possible therapeutic strategy to enhance radiosensitivity as well as to determine possible underlying mechanisms. 


\section{Cellular Physiology Cell Physiol Biochem 2017;44:778-791 \begin{tabular}{l|l} 
and BiOChemistry Publisnea onIne: November 23, 2017 & $\begin{array}{l}\text { (c) } 2017 \text { The Author(s). Published by S. Karger AG, Basel } \\
\text { www.karger.com/cpb }\end{array}$
\end{tabular} Zou et al.: Knockdown of CAVEOLIN-1 Increases Radiosensitivity in TNBC Cells}

\section{Materials and Methods}

\section{Antibodies and reagents}

Antibodies specific for CAV-1 and Histone H3 were purchased from Cell Signaling Technologies (Danvers, MA, USA); EGFR antibody was from BD Biosciences (CA, USA); phosphorylated DNA-PKcs (DNAPK catalytic subunit) (Thr2609) antibody was purchased from Biolegend (San Diego, CA, USA); antibodies against Histone H2A.x phosphor (pS139) and GAPDH were from Epitomics (CA, USA); KU70/80 antibody was obtained from Anbo Biotechnology Co. Ltd. (CA, USA), and 4',6-diamidino-2-phenylindole (DAPI) and Antifade mounting media were purchased from Beyotime Institute of Biotechnology (Shanghai, China).

\section{Cell culture}

The human breast cancer BT474, SKBR3, Hs578T and MDA-MB-231 cell lines were purchased from the Cell Bank of the Chinese Academy of Sciences (Shanghai, China). The Hs578T cell line was cultured in highglucose DMEM (Gibco, Grand Island, NY, USA) supplemented with 10\% foetal bovine serum (FBS) (Gibco) and $0.01 \mathrm{mg} / \mathrm{ml}$ insulin (Invitrogen, Carlsbad, CA, USA). BT474 cells were grown in high-glucose DMEM supplemented with 10\% FBS. SKBR3 and MDA-MB-231 cell lines were cultivated in RPMI-1640 medium (Gibco) supplemented with $10 \%$ FBS. All cells were incubated in a humidified incubator at $37^{\circ} \mathrm{C}$ with a $5 \%$ $\mathrm{CO}_{2}$ atmosphere and maintained in a logarithmic growth phase for all the experiments.

\section{Radiation exposure}

Specific irradiation at a dose ranging from 2 to 8 Gy was generated using a $1060 \mathrm{kV}$ industrial RS 2000 Biological X-ray irradiator (Rad Source Technologies, Inc., Alpharetta, GA). Cell samples were seeded either in plates or cell culture flasks and placed inside the exposure chamber. Cells were treated with the indicated single dose of X-rays at a dose rate of $1.151 \mathrm{~Gy} / \mathrm{min}$ at room temperature (RT), and a radiation output of 160 $\mathrm{kV}, 25 \mathrm{~mA}$ with a $0.3 \mathrm{~mm}$ Cu Filter.

\section{Cell transfection}

Three siRNA oligonucleotides directed against CAV-1 and a negative control siRNA (RiboBio Co. Ltd., Guangzhou, China) were applied in the present study. The sequences of small interfering RNA (siRNA) targeting CAV-1 were as follows: si-h- CAV-1_001, (sense) 5'-CAGGGCAACAUCUACAAGCdTdT-3' and (antisense) 3'-dTdTGUCCCGUUGUAGAUGUUCG-5; si-h-CAV-1_002, (sense) 5'-GCAAAUACGUAGACUCGGAdTdT-3' and (antisense) 3'-dTdTCGUUUAUGCAUCUGAGCCU-5'; si-h-CAV-1_003, (sense) 5'-GCAGUUGUACCAUGCAUUAdTdT-3' and (antisense) 3'-dTdT CGUCAACAUGGUACGUAAU-5'. Briefly, $1 \times 10^{5}$ cells were plated in 6-well plates, incubated for $24 \mathrm{~h}$ and then transfected with siRNA ( $50 \mathrm{nM}$ ) using Lipofectamine 2000 reagent (Carlsbad, CA, USA) and OPTI-MEM reduced serum media (Gibco). After 4-6 h, the medium was replaced. At $48 \mathrm{~h}$ after transfection, cells were collected for western blot analysis with or without irradiation treatment.

\section{Subcellular fractionation and western immunoblotting}

Cytoplasmic and nuclear extracts were prepared according to the instructions of a Nuclear and Cytoplasmic Protein Extraction Kit (Beyotime) at the indicated times following irradiation. Total cell lysates were collected using Cell Lysis Buffer for western blotting and IP (Beyotime). The protein concentration was determined using a BCA protein assay kit (Beyotime). Equal amounts of protein were separated on 8-12\% SDS-PAGE gels and transferred to PVDF membranes (Millipore, USA). Membranes were then blocked with $5 \%$ non-fat milk containing $0.1 \%$ Tween- 20 at RT for $1 \mathrm{~h}$, incubated with primary antibodies at $4^{\circ} \mathrm{C}$ overnight [antibodies against EGFR $(1: 1,000)$, CAV-1 $(1: 2,000)$, GAPDH $(1: 10,000)$, Histone H3 $(1: 1,000)$, and KU70/80 (1:500)] and subsequently incubated with secondary antibody. To confirm equal protein loading, GAPDH was used as a cytoplasmic internal control, and Histone H3 was used as a nuclear internal control. Peroxidase activity was visualized with Pierce Super Signal West Pico Chemiluminescent Substrate (Pierce, USA). The signal intensity was determined densitometrically using Quantity One Software, version 1.5 (Bio-Rad, CA, USA).

Immunofluorescence and confocal microscopy

A total of $2 \times 10^{4}$ cells was seeded onto glass slides that were placed in 24-well plates. After $24 \mathrm{~h}$ to allow cell adherence, siRNA transfection was performed. After $48 \mathrm{~h}$, cells were irradiated with 4 Gy X-ray 


\section{Cellular Physiology Cell Physiol Biochem 2017;44:778-791 \begin{tabular}{l|l|l}
\hline and Biochemistry 10.1159/000485291 & $\begin{array}{l}\text { C) } 2017 \text { The Author(s). Published by S. Karger AG, Basel } \\
\text { www.karger.com/cpb }\end{array}$
\end{tabular} \\ Zou et al.: Knockdown of CAVEOLIN-1 Increases Radiosensitivity in TNBC Cells}

and then incubated at $37^{\circ} \mathrm{C}$ for the indicated times. Thereafter, cells were fixed with $4 \%$ paraformaldehyde for $15 \mathrm{~min}$, washed with phosphate-buffered saline (PBS) (3 times, 5 min each) and then permeabilized with $0.5 \%$ Triton X-100 diluted in PBS for 15 min. After being washed with PBS, samples were blocked with blocking buffer (5\% normal goat serum) at RT for $1 \mathrm{~h}$ and incubated with primary antibody diluted in blocking buffer at $4^{\circ} \mathrm{C}$ overnight [antibodies against p-DNA-PKcs (1:100), $\gamma$-H2A.x (1:50), and EGFR (1:50)]. After being washed with PBS, cells were incubated with Alexa Fluor 555-donkey anti-rabbit IgG (H+L)- or Alexa Fluor 488-donkey anti-mouse IgG $(\mathrm{H}+\mathrm{L})$-conjugated secondary antibody (1:200) at RT for $1 \mathrm{~h}$ in the dark. After being washed, cells were incubated with DAPI at RT for $10 \mathrm{~min}$. Glass slides were then washed with PBS and were mounted in antifade mounting media. Fluorescence images were obtained using a Leica confocal laser scanning microscope equipped with Leica Confocal Software (Wetzlar, Germany) or an Olympus fluorescence microscope. At least 300 cells were counted and assessed in a blinded manner for each data point. Image analysis was performed using IPP Software, version 6.0.

\section{Colony formation assay}

Cells were transfected with 003 CAV-1 siRNA or negative siRNA for $48 \mathrm{~h}$, and trypsinized cells were seeded in $60 \mathrm{~mm}^{2}$ plates. Then, $24 \mathrm{~h}$ after plating, cells were exposed to X-ray doses ranging from 2-10 Gy, and 10-14 days after irradiation, cells were fixed with $95 \%$ ethanol and stained with $0.1 \%$ crystal violet (dissolved in 1:19 ethanol: PBS) at RT for 15 min. Excess dye was removed by gentle washing with distilled water. The colonies ( $>50$ cells) were manually counted with the aid of a microscope. Plating efficiencies were calculated as follows: number of colonies formed/number of cells plated (non-irradiated). The surviving clonogenic fraction of irradiated cells was normalized to the plating efficiency of non-irradiated controls and calculated as follows: numbers of colonies formed (irradiated)/ [numbers of cells plated (irradiated) $\times$ plating efficiency]. Each point on the survival curve represents the mean surviving fraction from three independent experiments. GraphPad Prism 5 was used to fit the cell survival curve.

\section{Apoptosis detection}

Cells were seeded in 6-well plates at a density of $1 \times 10^{5}$ cells/well. At $48 \mathrm{~h}$ after siRNA transfection, cells were left untreated or irradiated with a single dose of 6-8 Gy and then incubated at $37^{\circ} \mathrm{C}$ for another $48 \mathrm{~h}$. Both attached and detached cells were collected for apoptosis analysis using an Annexin V-fluorescein isothiocyanate (FITC) Apoptosis Detection Kit (KeyGen Biotech, Nanjing, China). FACS analysis was performed on FACScan flow cytometer (Becton-Dickinson Co., USA) using CellQuest software (BectonDickinson).

\section{Cell cycle analysis}

Cells were treated and harvested as described above, and a Cell Cycle and Apoptosis Analysis Kit (Beyotime) was used for cell analysis. DNA content analysis was performed using a FACScan flow cytometer (Becton-Dickinson) with ModFit LT software (Becton-Dickinson).

\section{Statistical analysis}

Student's t-test was used to compare data between two groups. Values are expressed as the mean \pm SD of three independent experiments. P-values $<0.05$ were considered statistically significant and are indicated where appropriate in the figures and legends. To control Type I errors, the Bonferroni correction was used when $n$ dependent or independent data set hypotheses were tested, with an adjusted statistical significance level of $0.05 / \mathrm{n}$ ( $\mathrm{n}$ indicates the number of separate tests). All statistical analyses were performed using SPSS software version 17.0 (Chicago, IL, USA).

\section{Results}

Protein expression and inherent radiosensitivity in breast cancer cell lines

As shown in Fig. 1A, the expression of HER-2, EGFR and CAV-1 protein was evaluated in four breast cancer cell lines. We found that EGFR and CAV-1 are both over-expressed in two BLBC cell lines (Hs578T and MDA-MB-231) [32]. In contrast, the other two cell lines (BT474 and SKBR3), which are HER-2 positive, barely express CAV-1 independent of EGFR 


\section{Cellular Physiology Cell Physiol Biochem 2017;44:778-791 and Biochemistry \begin{tabular}{l|l} 
DOI: 10.1159/000485291 & (c) 2017 The Author(s). Published by S. Karger AG, Basel \\
www.karger.com/cpb
\end{tabular}

Fig. 1. (A) Western blot analysis showing HER-2, EGFR, and CAV-1 expression levels in four breast cancer cell lines. GAPDH served a loading control. The data shown are representative of three independent experiments. (B) Inherent radiosensitivity differs in breast cancer cell lines with distinguishable CAV-1 expression. Cells were exposed to radiation (2, 4, 6, 8 and $10 \mathrm{~Gy})$, and culture medium was changed every 3-5 days. Cells were cultured for 10-14 days to allow colony formation and then stained. Colonies with $>50$ cells were counted, and survival curves were constructed based on calculation of the survival fraction after each dose of radiation. The data shown are the mean \pm SD of three independent experiments. ${ }^{*} \mathrm{p}<0.05$ compared to MDAMB-231 cells.

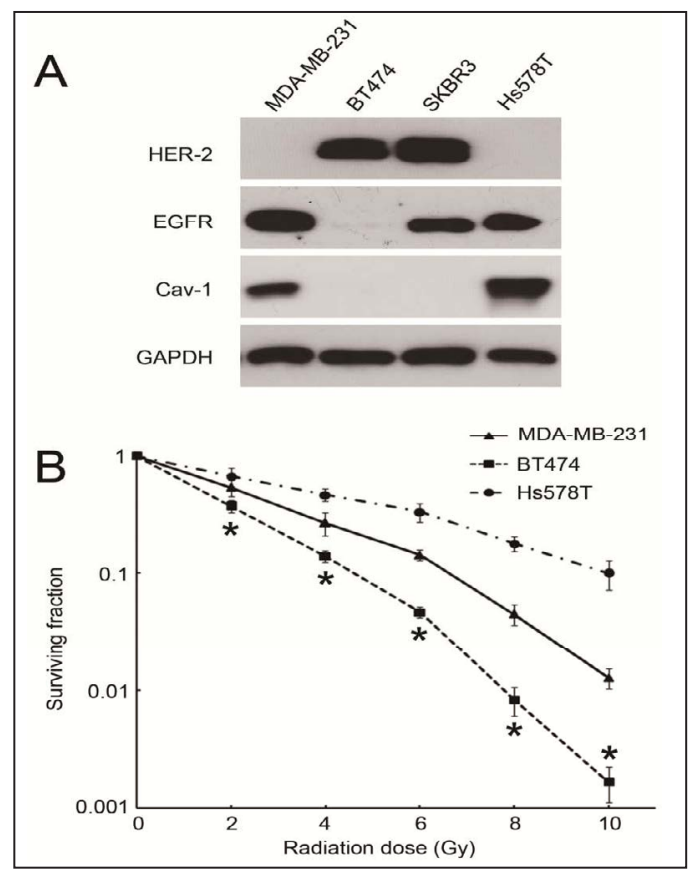

Fig. 2. (A) Comparison of the silencing effect of CAV1 siRNA (001, 002 and 003) on the Hs578T cell line. (B) Specific inhibition effect of CAV-1 siRNA on two breast cancer cell lines. Con: Control (cells without treatment); 003 si: 003 CAV-1 siRNA; Mock: all reagents without siRNA; NC si: Negative siRNA. GAPDH was used as the internal control. The histogram presents the means $\pm \operatorname{SD}(n=3)$. ${ }^{*} \mathrm{p}<0.008$ vs. control group.

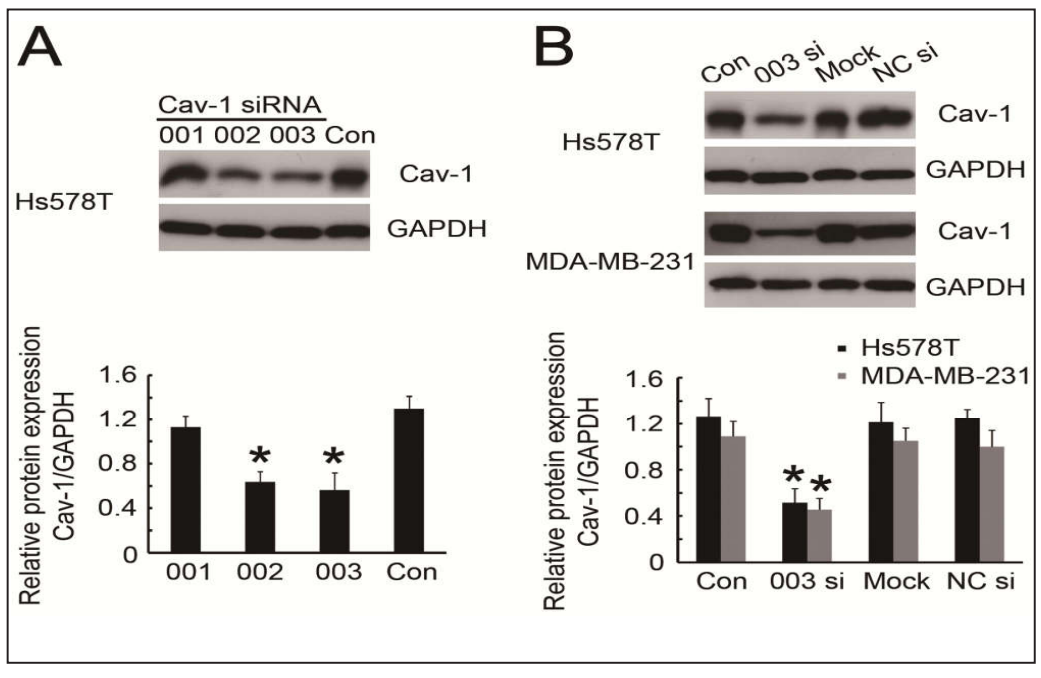

expression. Next, we examined the inherent radiosensitivity of BT474, MDA-MB-231 and Hs578T cell lines. We observed that the BT474 cell line is more sensitive to irradiation than radioresistant MDA-MB-231 and Hs578T cells (Fig. 1B). These results indicated that overexpression of CAV-1 might be a factor governing radioresistance in BLBC cell lines.

Radiation-induced EGFR nuclear translocation was abrogated by CAV-1 siRNA treatment

In other cancer cell lines, EGFR has been reported to translocate to the nucleus following radiotherapy and confer resistance to radiation $[33,34]$. In the present study, we evaluated whether EGFR translocates to the nucleus after ionizing radiation in two BLBC cell lines. At multiple time points following irradiation, cytoplasmic and nuclear extracts were examined for EGFR expression. As seen in Fig. 3, radiation exposure of two cell lines gradually increased EGFR within the nuclear fraction, while the amount of EGFR in the cytosolic fraction declined, indicating translocation of EGFR from the cytoplasm to the nucleus rather than increased protein expression. In Fig. 1, we observed that radioresistance in BLBC cells might 
Fig. 3. Effect of radiation, CAV-1 siRNA or both on EGFR nuclear translocation and proteins associated with DNA repair. (A) Hs578T and MDA-MB-231 cells were exposed to $4 \mathrm{~Gy}$ in the absence or presence of CAV-1 siRNA (pretreated $48 \mathrm{~h}$ prior to radiation) and collected at specified time points following radiation. GAPDH was used as a cytoplasm loading control; Histone $\mathrm{H} 3$ was used as a nucleus loading control. (B) The data in the bar graph represent the mean $\pm \mathrm{SD}$ of triplicate samples. Solid line: $4 \mathrm{~Gy}$; long dashlines: CAV-1 siRNA + 4 Gy. ${ }^{*} \mathrm{p}<0.05$ vs. 4 Gy control group; $\# \mathrm{p}<0.05$ vs. basal level.
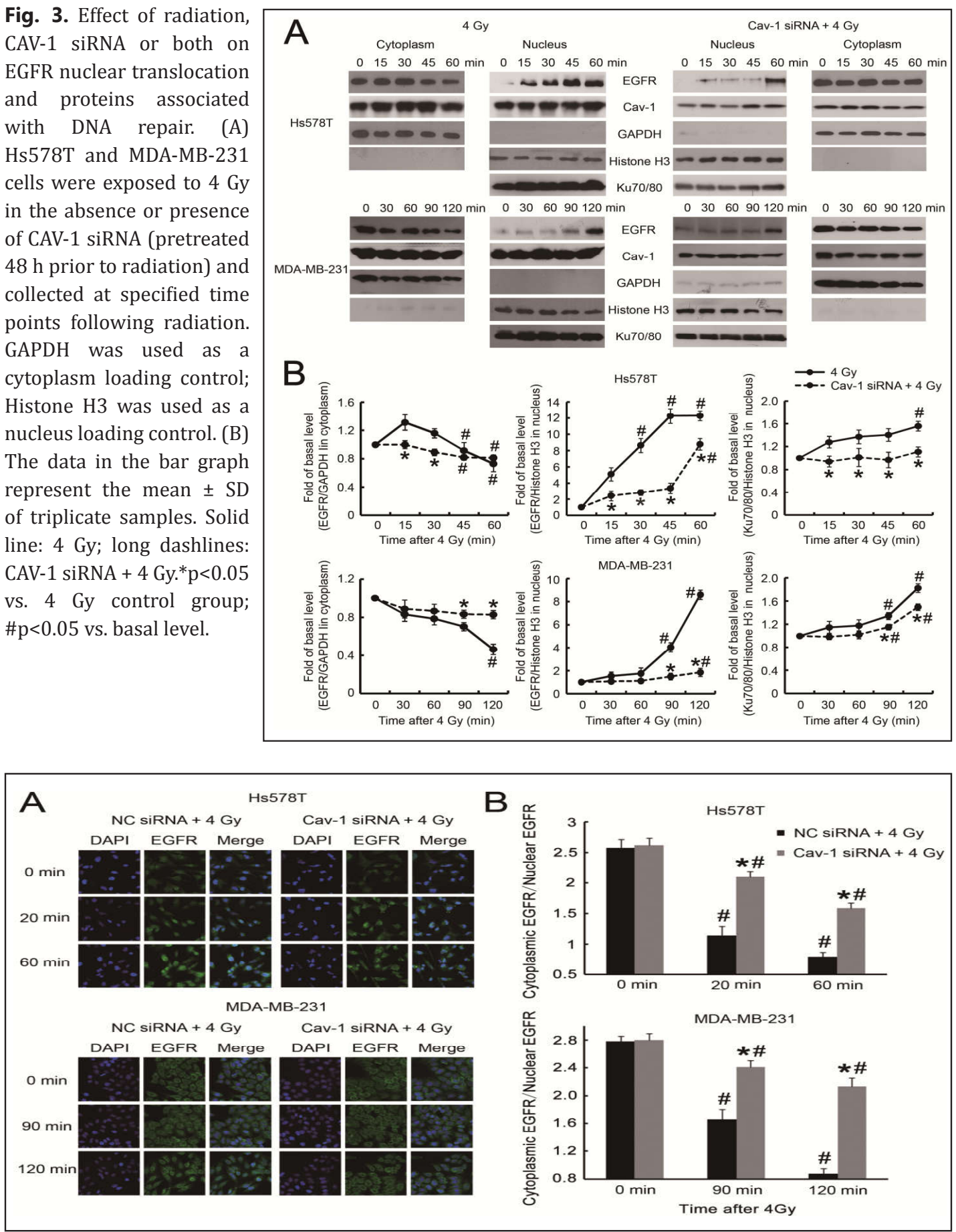

Fig. 4. (A) Immunofluorescence (IF) confocal microscopy analysis of EGFR localization at the indicated time points after 4 Gy irradiation in the presence of NC siRNA or CAV-1 siRNA in Hs578T and MDA-MB-231 cell lines. Cells were stained for DNA (DAPI, blue) and EGFR (Alexa Fluor 488, green). One representative image of three independent experiments is displayed (magnification $\times 400$ ). (B) The ratio of cytoplasmic EGFR to nuclear EGFR was plotted against time of IF analysis after 4 Gy irradiation. The data shown are the mean \pm SD of three independent experiments. ${ }^{*} \mathrm{p}<0.003$ vs. NC siRNA +4 Gy group; $\# \mathrm{p}<0.003$ vs. basal level.

be correlated with CAV-1 overexpression, and activation of CAV-1 has been reported to be involved in EGFR nuclear trafficking [14]. Hence, knock down of $C A V-1$ was next conducted to 


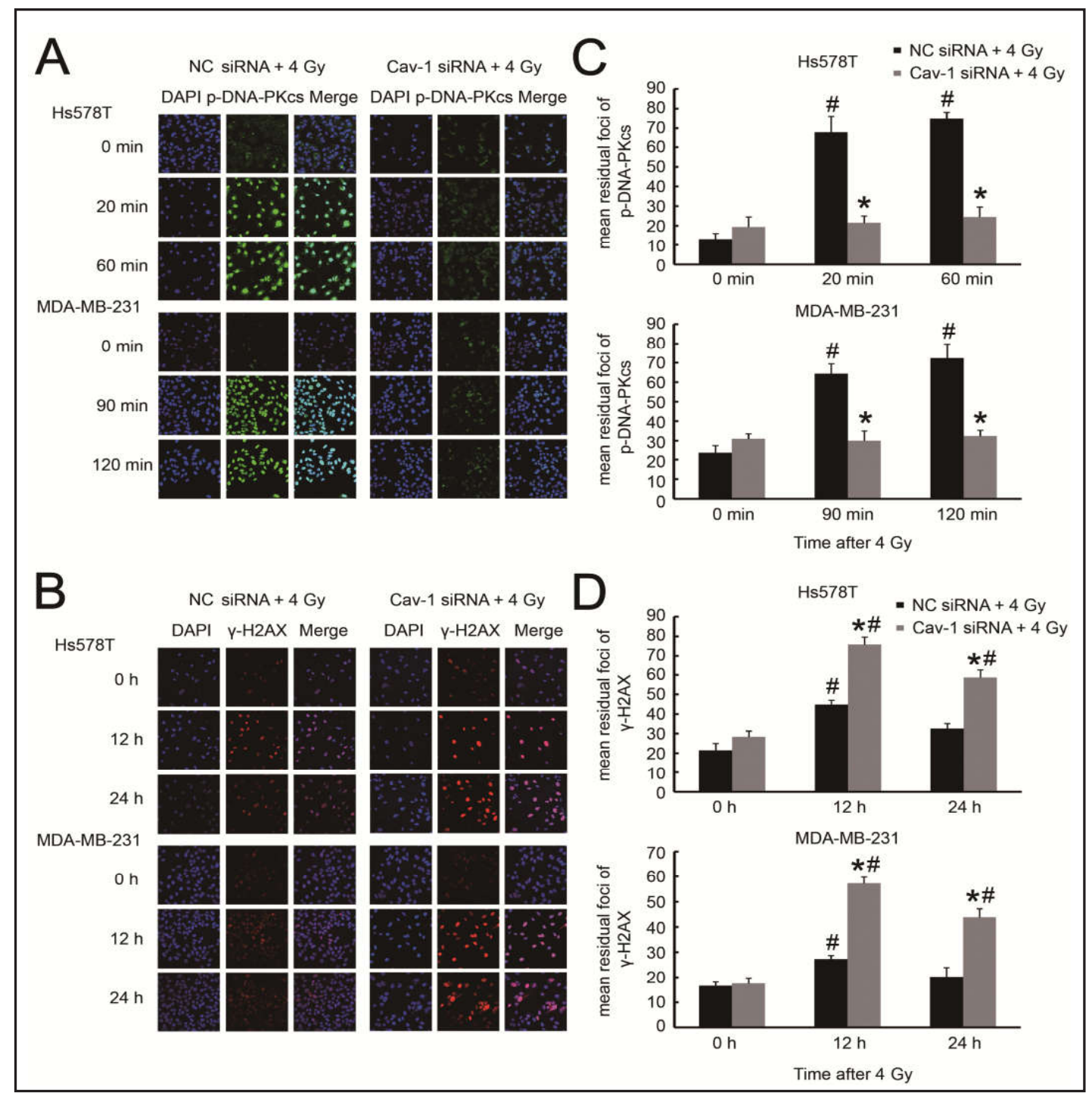

Fig. 5. Effect of radiation, CAV-1 siRNA or both on DNA repair and damage in Hs578T and MDA-MB-231 cell lines. Cells were exposed to $4 \mathrm{~Gy}$ in the presence of NC siRNA or CAV-1 siRNA (pretreated $48 \mathrm{~h}$ prior to radiation) and collected at various time points following irradiation. IF was used to analyse the nuclear expression of p-DNA-PKcs and $\gamma$-H2AX. (A) Shown are representative nuclei stained for p-DNA-PKcs (Alexa Fluor 488, green) and DNA (DAPI, blue) after the specified treatments (magnification $\times 400$ ). (B) Shown are representative nuclei stained for $\gamma-\mathrm{H} 2 \mathrm{AX}$ (Alexa Fluor 555, red) and DNA (DAPI, blue) after the specified treatments (magnification $\times 400$ ). (C and D) The mean number of residual p-DNA-PKcs and $\gamma$-H2AX foci was plotted against time of IF analysis after 4 Gy irradiation. The data shown are the mean \pm SD of three independent experiments. *p<0.003 vs. NC siRNA + 4 Gy group; $\#$ p<0.003 vs. basal level.

illustrate its role in the process of EGFR nuclear localization. As shown in Fig. 2A, a reduction in CAV-1 in the Hs578T cell line was most obvious in 003 CAV-1-siRNA transfected cells. Thus, we chose 003 CAV-1 siRNA for the following experiments. Two BLBC cell lines were transfected with control siRNA or CAV-1 siRNA, and cells were collected $48 \mathrm{~h}$ later to validate transfection efficiency (Fig. 2B). In cells transfected with CAV-1 siRNA, the radiation-induced nuclear EGFR translocation process was impaired and the EGFR peak was delayed (Fig. 3). These observations were further confirmed with confocal microscopy (Fig. 4). EGFR (green) disappeared from its peri-nuclear location and was detected within the nucleus (DNA in 
Fig. 6. Knockdown of CAV-1 sensitized MDA-MB-231 cells to radiation-induced cell death. MDA-MB-231 cells were transiently transfected with CAV-1 siRNA or Negative siRNA (NC siRNA), replated and irradiated with single doses of 2-10 Gy. Cells were cultured for 10-14 days, and survival curves were constructed based on calculation of the survival fraction after each dose of radiation. The data shown are the mean \pm SD of three independent experiments. ${ }^{*} \mathrm{p}<0.05$ vs. the untransfected control group.
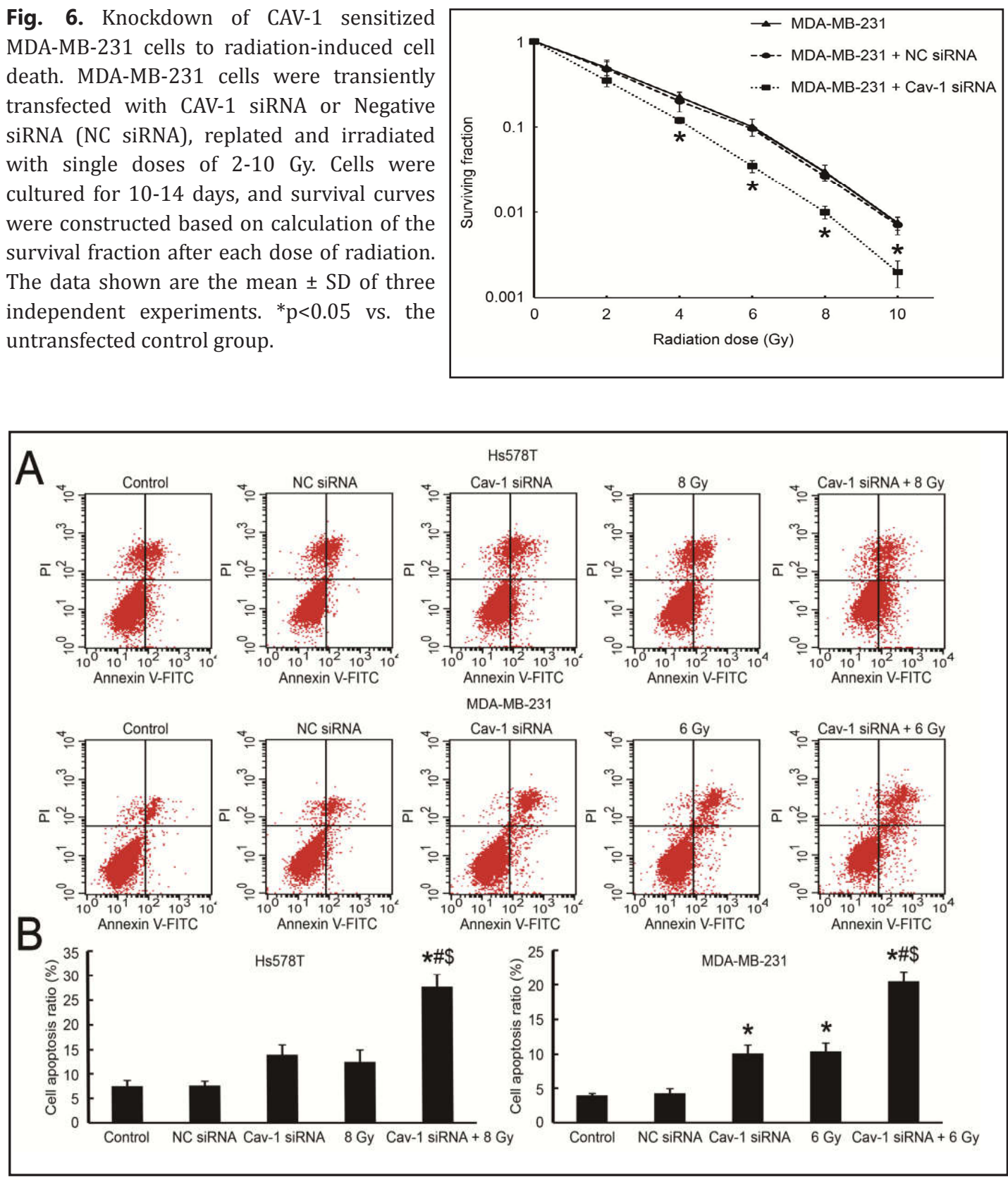

Fig. 7. Effect of radiation, CAV-1 siRNA or both on cell apoptosis induction in Hs578T and MDA-MB-231 cell lines. (A) Hs578T and MDA-MB-231 cells were exposed to a single radiation dose of 8 Gy or 6 Gy respectively in the presence or absence of siRNA treatment. Then, $48 \mathrm{~h}$ after irradiation, detached and adherent cells were collected. Flow cytometry analysis using Annexin V-FITC and propidium iodide (PI) double staining was performed to detect the apoptosis ratio. (B) Comparison of the total apoptosis rate, including early and late apoptosis populations. Early apoptotic cells were positive for Annexin V-FITC and negative for PI. Late apoptotic cells were positive for both Annexin V-FITC and PI. The displayed data are the mean \pm SD of three independent experiments. ${ }^{*} \mathrm{p}<0.005$ vs. control group. $\# \mathrm{p}<0.005$ vs. CAV- 1 siRNA group. $\$ \mathrm{p}<0.005$ vs. radiation only ( 8 Gy or $6 \mathrm{~Gy}$ ) group.

blue) in cells transfected with negative siRNA. In contrast, in cells transfected with CAV-1 siRNA, radiation-induced EGFR nuclear transport was inhibited. 


\section{$\begin{array}{lll}\text { Cellular Physiology } & \text { Cell Physiol Biochem 2017;44:778-791 } \\ \text { DOI: 10.1159/000485291 } & 0 \text { 2017 The Author(s). Published by S. Karger AG, Basel }\end{array}$

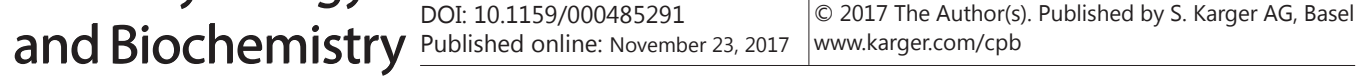 \\ Zou et al.: Knockdown of CAVEOLIN-1 Increases Radiosensitivity in TNBC Cells}

CAV-1 siRNA treatment followed by ionizing radiation compromised DNA repair and prolonged DNA damage

To determine whether CAV-1-mediated blockage of nuclear EGFR transport affects DNA repair following irradiation, we observed the expression of the nuclear proteins $p$-DNA-PKcs and KU70/80 via immunofluorescence and western blotting (Fig. 5A and 3A). Irradiation resulted in a time-dependent increase in p-DNA-PKcs and KU70/80 expression, indicating that DNA repair proteins emerged after irradiation. Pretreatment with $C A V-1$ siRNA led to declination of p-DNA-PKcs and KU70/80 expression at the indicated times post-irradiation compared to radiation alone in two BLBC cell lines, which showed that DNA repair was impeded. Next, we quantified residual DNA-double strand breaks (DSBs) at $12 \mathrm{~h}$ and $24 \mathrm{~h}$ after radiation exposure in two cell lines. As depicted in Fig. 5B, few foci representing $\gamma-\mathrm{H} 2 \mathrm{AX}$, which is a marker of DNA damage, could be observed in non-irradiated cells [35]. Radiation induced a significant increase in $\gamma$-H2AX $12 \mathrm{~h}$ after irradiation in the presence or absence of $C A V-1$ siRNA. However, $\gamma$-H2AX decreased after $12 \mathrm{~h}$ in cells transfected with negative siRNA and returned to almost baseline levels within $24 \mathrm{~h}$ after irradiation. In contrast, $\gamma \mathrm{H} 2 \mathrm{AX}$ foci formation was prolonged and remained constant $24 \mathrm{~h}$ after irradiation in cells exposed to $C A V-1$ siRNA, supporting a loss of DNA repair ability and sustained DNA damage.

Basal-like TNBC cell line was sensitized to ionizing radiation by knockdown of CAV-1

The radiosensitivity of MDA-MB-231 cells transfected with CAV-1 siRNA and MDAMB-231 cells transfected with negative siRNA was assessed using a colony formation assay. As shown in Fig. 6, cells transfected with CAV-1 siRNA were markedly radiosensitized, with

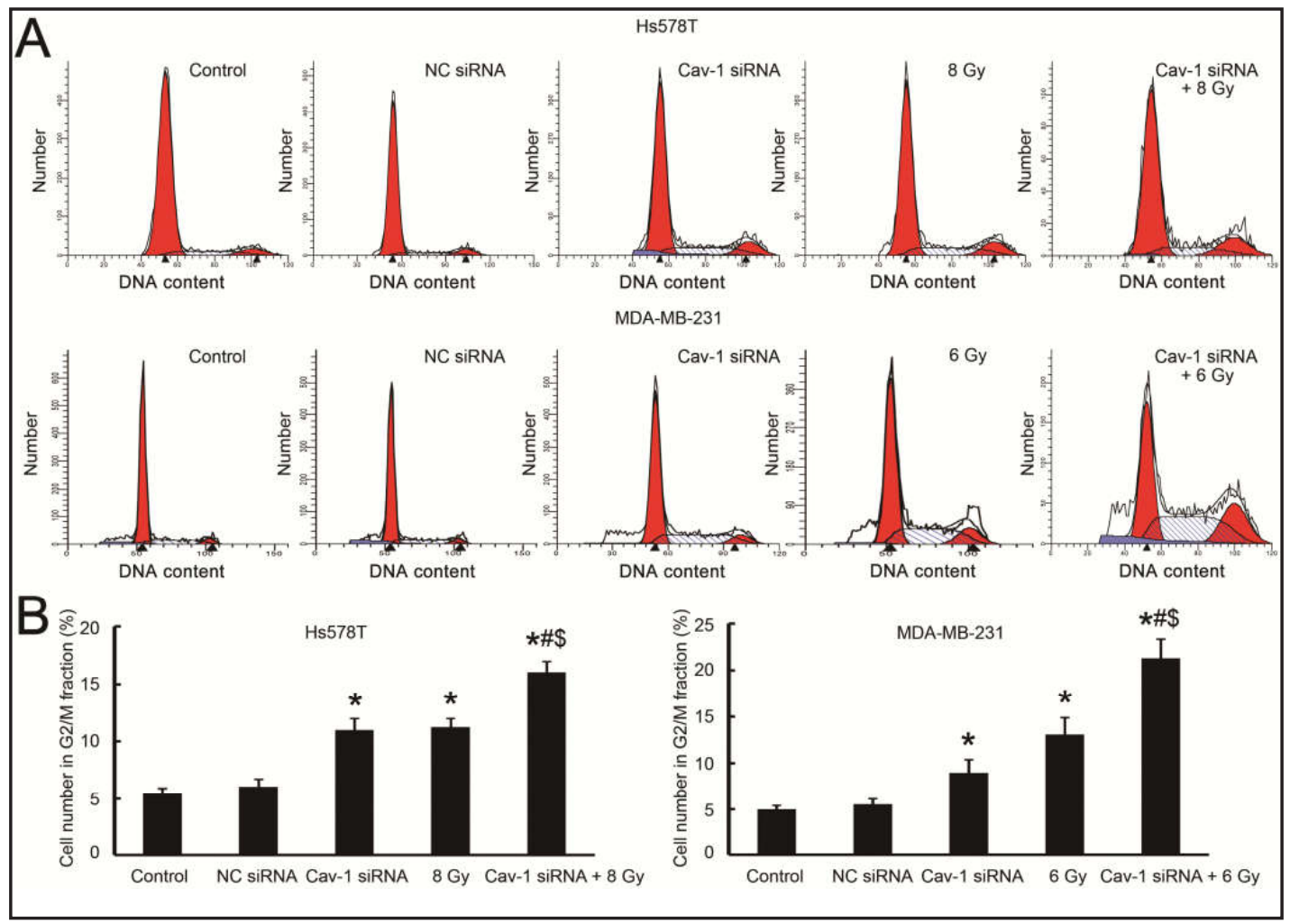

Fig. 8. Effect of radiation, CAV-1 siRNA or both on cell cycle distribution in Hs578T and MDA-MB-231 cell lines. (A) Hs578T and MDA-MB-231 cells were exposed to a single radiation dose of 8 Gy or 6 Gy respectively in the presence or absence of siRNA treatment. Then, $48 \mathrm{~h}$ after irradiation, detached and adherent cells were harvested. (B) Comparison of the percentage of the $G_{2} / M$ fraction. The displayed data are the mean \pm SD of three independent experiments. ${ }^{*} \mathrm{p}<0.005$ vs. control group. $\# \mathrm{p}<0.005$ vs. CAV-1 siRNA group. $\$ \mathrm{p}<0.005$ vs. radiation only (8 Gy or 6 Gy) group. 


\section{Cellular Physiology Cell Physiol Biochem 2017;44:778-791

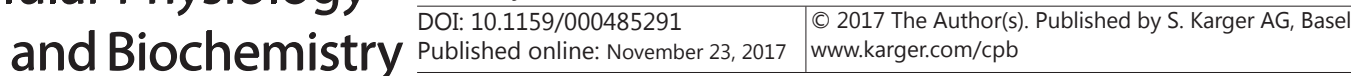 \\ Zou et al.: Knockdown of CAVEOLIN-1 Increases Radiosensitivity in TNBC Cells}

reduced radiation survival after varying doses of radiation and a sensitivity enhancement ratio (SER) of 1.359 , while cells transfected with negative siRNA were not sensitized to irradiation.

\section{Knockdown of CAV-1 enhanced radiation-induced cell apoptosis}

In this study, the radiosensitizing effects of $C A V-1$ siRNA were also investigated by examining the pro-apoptotic effects of $C A V$-1 siRNA combined with radiation in two BLBC cell lines. The proportion of apoptotic cells was determined with flow cytometry after treatment. The total apoptosis rate, including early and late apoptosis populations, was determined. The results revealed that in both cell lines, each treatment alone induced modest apoptosis, but the combined treatments enhanced the apoptosis rate to a greater extent (Fig. 7).

\section{Knockdown of CAV-1 altered cell cycle distribution}

Because the distribution of cells in the division cycle is an important determinant of radiosensitivity, with $S$-phase cells being the least radiosensitive and $G_{2} / M$ cells being the most radiosensitive, we examined cell cycle alterations $48 \mathrm{~h}$ after transfection, irradiation or both [36]. We found that irradiation alone augmented the $G_{2} / M$ phase fraction of MDAMB-231 cells, and $C A V-1$ siRNA treatment alone induced a slight $\mathrm{G}_{2} / \mathrm{M}$ arrest. However, the combination of si-CAV-1 and radiation increased $\mathrm{G}_{2} / \mathrm{M}$ arrest more significantly. Similar data were obtained in Hs578T cells (Fig. 8).

\section{Discussion}

The role of $C A V-1$ as a tumour suppressor gene or as a tumour promoter seems to strictly depend on cell type and tumour stage [37]. Given the controversy regarding the distribution of $C A V-1$ in breast cancer subtypes and its significance in breast carcinogenesis, we first analysed the protein level of CAV-1 in a panel of breast cancer cell lines with distinctive molecular profiles [32]. We found that there is no expression of CAV-1 in HER-2-positive cell lines (BT474 and SKBR3), which showed an inverse correlation between HER-2 and CAV-1. This is consistent with the finding that $C A V-1$ is a tumour suppressor gene that is seldom expressed in HER-2 (+) invasive ductal breast cancer [38]. Meanwhile, our results showed that CAV-1 is highly expressed in two BLBC cell lines with EGFR expression, which is in accordance with previous studies that CAV-1 expression was strongly associated with 'basal-like' immunophenotype breast tissue samples [31]. Witkiewicz et al. were the first to verify that the prognostic value of CAV-1 in TNBC patients is compartment-specific: loss of stromal CAV-1 expression predicts poor clinical outcome in triple-negative and basal-like breast cancers, while the levels of tumour epithelial CAV- 1 had no prognostic significance [39]. In our study, we examined the total CAV-1 expression in several cell lines, which did not discriminate between epithelial and stromal cells. The results called into question whether highly expressed CAV-1 in BLBC cell lines plays a functional role in radiation resistance aside from its role as a surrogate marker for basal differentiation.

It is generally accepted that EGFR localizes to the nucleus upon ligand-independent stimuli [12-14]. Our results again revealed that in EGFR over-expressing BLBC cell lines, EGFR translocates from the cytoplasm to the nucleus following ionizing radiation. EGFR inhibition has proven to be ineffective in both preclinical experiments and in clinical trials as adjuvant treatment for TNBC patients $[40,41]$. Hence, new targeted therapy that can inhibit EGFR nuclear trafficking is being extensively investigated. Dittamann et al. provided evidence that ionizing radiation resulted in fast src kinase stabilization, activation and subsequent srcmediated CAV-1 Y14 and EGFR Y845 phosphorylation [14]. Blockage of src activity with the src-specific inhibitor PP2 inhibits CAV-1 phosphorylation and decreases nuclear transport of EGFR [14]. Dasatinib, a highly potent dual src/bcr-abl kinase inhibitor, has recently been reported as a radiosensitizer by interfering with EGFR nuclear localization in HNSCC cells [42]. Consistent with the findings of other researchers, though using a different methodology, 
we confirmed that specific CAV-1 siRNA alone could abrogate EGFR nuclear translocation upon irradiation. We and others have demonstrated that the activation and presence of CAV1 both play a prominent role in ionizing radiation-induced EGFR nuclear accumulation.

Approximately $19.5 \%$ of TNBC patients are BRCA1 and BRCA2 mutation carriers and thus have defective DNA repair abilities [43]. The two BLBC cell lines used in our experiments both express wild-type BRCA1 protein and are proficient in radiation-induced DNA DSB repair [44, 45]. KU70/80 and DNA-PKcs are of vital importance in NHEJ, the predominant pathway for the repair of radiation-induced DSBs in human cells [45]. Our results showed that in two BLBC cell lines, when cells were pretreated with CAV-1 siRNA, DNA-PKcs phosphorylation at T2609 and the increase in KU70/80 following irradiation were specifically abolished, accompanied by increased and sustained DNA damage. Moreover, Zhu et al. observed decreased levels of phospho-ATM (Ser 1981) and phospho-checkpoint kinase 2 (CHK2) (Thr 68) and fewer BRCA1 foci upon caveolin-1 knockdown [46]. Taken together, both our data and that of others have demonstrated that caveolin-1 knockdown mitigates the ability of cells to repair DNA damage.

Kimple and colleagues suggested that the cell cycle distribution is altered at different times after irradiation; $G_{2}$ arrest was most obvious $24 \mathrm{~h}$ after radiation, followed by a reduction at $48 \mathrm{~h}$ [47]. Hence, the cell cycle re-distribution we analysed $48 \mathrm{~h}$ post-radiation might not correlate with the maximum $\mathrm{G}_{2} / \mathrm{M}$ arrest, but a prolonged and persistent radiationinduced $\mathrm{G}_{2} / \mathrm{M}$ cell cycle arrest was observed in the combined group. Our experiments also revealed that $C A V-1$ siRNA alone exhibited a pro-apoptotic function in two BLBC cell lines (Fig. 7). When used in combination with radiation, the proportion of apoptotic cells increased. Several studies have also suggested that caveolin-1 acts as a suppressor of breast cancer invasiveness and metastasis [48, 49]. Although the role of CAV-1 in tumorigenesis is controversial, taken together, our data confirmed that CAV- 1 can act as a pro-survival factor in BLBC, and $C A V-1$ siRNA itself has certain antitumor effects in vitro. Bonuccelli et al. reported that the $\mathrm{P} 132 \mathrm{~L}$ mutation in CAV-1 significantly increased cell migration, invasion and metastasis formation [50]. Therefore, further examination of sporadic CAV1 mutations and radiosensitivity are ongoing in our laboratory.

Although CAV-1 siRNA enhanced radiosensitivity in both MDA-MB-231 and Hs578T cells, inherent radiosensitivity varied between the two cell lines [51]. We noted that p-DNAPKcs could be detected as early as $20 \mathrm{~min}$ after exposure of cells to 4 Gy radiation and was evident at $1 \mathrm{~h}$ in Hs578T cells (Fig. 5A). Meanwhile, irradiation-induced p-DNA-PKcs was first detected after $1 \mathrm{~h}$ and peaked $2 \mathrm{~h}$ post-irradiation in MDA-MB-231 cells. Other researchers have shown that EGFR physically interacts with DNA-PK and regulates its activity [15]. This is in accordance with the time that EGFR began to traffic from the cytoplasm to the nucleus in each cell line. The differential timing of EGFR mobilization and DNA-PKcs phosphorylation in two BLBC cell lines in response to irradiation may, to some extent, reflect a plausible phenomenon that different start times of nuclear EGFR-mediated DNA repair may be related to different radiosensitivities of cell lines: the sooner the nuclear EGFR emerged, the earlier DNA-PKcs was phosphorylated at T2609, and then, the cells are more likely to be radioresistant and vice versa. Consistent with this speculation, the results of the apoptosis analysis we performed showed that the radiation dose in MDA-MB-231 cell line was 6 Gy and was enough to result in apoptosis. However, in the Hs578T cell line, a 6 Gy single dose of radiation could not induce a comparative extent of apoptosis until the dose increased to $8 \mathrm{~Gy}$, which manifests the likelihood of stronger radioresistance in Hs578T cells.

To sum up, in the present study, we not only found that CAV-1 is highly expressed in radioresistant BLBC cell lines compared to radiosensitive cells but also for the first time verified that CAV-1 might play a pro-survival role in the biology of basal-like and triplenegative breast tumours and demonstrated that $C A V-1$ siRNA could be a radiosensitizer in BLBC cells. In our experiments, this radiosensitizing function might be due in part to blockage of nuclear EGFR translocation, which led to retardation of DNA repair following radiationinduced DSBs, and may be partially correlated with cell cycle re-distribution and apoptosis induction. These findings suggest that treatment strategies that incorporate $C A V-1$ siRNA 


\section{Cellular Physiology Cell Physiol Biochem 2017;44:778-791 \begin{tabular}{l|l|l} 
and Biochemistry Published onlIne: November 23, 2017 & $\begin{array}{l}\text { (c) } 2017 \text { The Author(s). Published by S. Karger AG, Basel } \\
\text { www.karger.com/cpb }\end{array}$
\end{tabular} \\ Zou et al.: Knockdown of CAVEOLIN-1 Increases Radiosensitivity in TNBC Cells}

may be considered promising for sensitization of BLBC cells to irradiation. The combination of $C A V-1$ siRNA and radiation warrants further investigation in tumour models in vivo for potential translation into clinical practice.

\section{Abbreviations}

TNBC (triple negative breast cancer); BLBC (basal-like breast cancer); EGFR (epidermal growth factor receptor); DNA-PK (DNA dependent protein kinase); NHEJ (non-homologous end-joining); CAV-1 (CAVEOLIN-1); FBS (foetal bovine serum); RT (room temperature); PBS (phosphate-buffered saline); DSB (double strand breaks); SER (sensitivity enhancement ratio); IF (Immunofluorescence); PI (propidium iodide).

\section{Acknowledgements}

This work was supported by National Natural Science Foundation of China (No. 81172187, 81301929, 81372664, 81672984 and 81700348).

\section{Disclosure Statement}

The authors declare no conflict of interest.

\section{References}

1. Siegel RL, Miller KD, Jemal A: Cancer statistics, 2015. CA Cancer J Clin 2015;65:5-29.

2. Sorlie T, Perou CM, Tibshirani R, Aas T, Geisler S, Johnsen H, Hastie T, Eisen MB, Van de Rijn M, Jeffrey SS, Thorsen T, Quist H, Matese JC, Brown PO, Botstein D, Lonning PE, Borresen-Dale AL: Gene expression patterns of breast carcinomas distinguish tumor subclasses with clinical implications. Proc Natl Acad Sci USA 2001;98:10869-10874.

3. Valentin MD, da Silva SD, Privat M, Alaoui-Jamali M, Bignon YJ: Molecular insights on basal-like breast cancer. Breast Cancer Res Treat 2012;134:21-30.

4. Prise KM, Schettino G, Folkard M, Held KD: New insights on cell death from radiation exposure. Lancet Oncol 2005;6:520-528.

5. Yang JY, Xia W, Hu MC: Ionizing radiation activates expression of FOXO3a, Fas ligand, and Bim, and induces cell apoptosis. Int J Oncol 2006;29:643-648.

6. Langlands FE, Horgan K, Dodwell DD, Smith L: Breast cancer subtypes: response to radiotherapy and potential radiosensitisation. Br J Radiol 2013;86:20120601.

7. Kyndi M, Sorensen FB, Knudsen H, Overgaard M, Nielsen HM, Overgaard J: Estrogen receptor, progesterone receptor, HER-2, and response to postmastectomy radiotherapy in high-risk breast cancer: the Danish Breast Cancer Cooperative Group. J Clin Oncol 2008;26:1419-1426.

8. O’Rorke MA, Murray LJ, Brand JS, Bhoo-Pathy N: The value of adjuvant radiotherapy on survival and recurrence in triple-negative breast cancer: A systematic review and meta-analysis of 5507 patients. Cancer Treat Rev 2016;47:12-21.

-9. Rubin Grandis J, Melhem MF, Gooding WE, Day R, Holst VA, Wagener MM, Drenning SD, Tweardy DJ: Levels of TGF-alpha and EGFR protein in head and neck squamous cell carcinoma and patient survival. J Natl Cancer Inst 1998;90:824-832.

10. Messa C, Russo F, Caruso MG, Di Leo A: EGF, TGF-alpha, and EGF-R in human colorectal adenocarcinoma. Acta Oncol 1998;37:285-289.

11. Barbieri MA, Roberts RL, Gumusboga A, Highfield H, Alvarez-Dominguez C, Wells A, Stahl PD: Epidermal growth factor and membrane trafficking. EGF receptor activation of endocytosis requires Rab5a. J Cell Biol 2000;151:539-550.

12. Xu Y, Shao Y, Zhou J, Voorhees JJ, Fisher GJ: Ultraviolet irradiation-induces epidermal growth factor receptor (EGFR) nuclear translocation in human keratinocytes. J Cell Biochem 2009;107:873-880. 


\section{Cellular Physiology Cell Physiol Biochem 2017;44:778-791

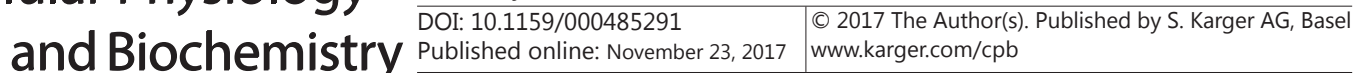 \\ Zou et al.: Knockdown of CAVEOLIN-1 Increases Radiosensitivity in TNBC Cells}

13. Khan EM, Heidinger JM, Levy M, Lisanti MP, Ravid T, Goldkorn T: Epidermal growth factor receptor exposed to oxidative stress undergoes Src- and caveolin-1-dependent perinuclear trafficking. J Biol Chem 2006;281:14486-14493.

14. Dittmann K, Mayer C, Kehlbach R, Rodemann HP: Radiation-induced caveolin-1 associated EGFR internalization is linked with nuclear EGFR transport and activation of DNA-PK. Mol Cancer 2008;7:69.

15. Bandyopadhyay D, Mandal M, Adam L, Mendelsohn J, Kumar R: Physical interaction between epidermal growth factor receptor and DNA-dependent protein kinase in mammalian cells. J Biol Chem 1998;273:1568-1573.

16. Dittmann K, Mayer C, Fehrenbacher B, Schaller M, Raju U, Milas L, Chen DJ, Kehlbach R, Rodemann HP: Radiation-induced epidermal growth factor receptor nuclear import is linked to activation of DNAdependent protein kinase. J Biol Chem 2005;280:31182-31189.

17. Dittmann K, Mayer C, Fehrenbacher B, Schaller M, Kehlbach R, Rodemann HP: Nuclear epidermal growth factor receptor modulates cellular radio-sensitivity by regulation of chromatin access. Radiother Oncol 2011;99:317-322.

18. Dittmann K, Mayer C, Rodemann HP: Inhibition of radiation-induced EGFR nuclear import by C225 (Cetuximab) suppresses DNA-PK activity. Radiother Oncol 2005;76:157-161.

19. Cai T, Wang H, Chen Y, Liu L, Gunning WT, Quintas LE, Xie ZJ: Regulation of caveolin-1 membrane trafficking by the Na/K-ATPase. J Cell Biol 2008;182:1153-1169.

20. Palacios-Ortega S, Varela-Guruceaga M, Algarabel M, Ignacio Milagro F, Alfredo Martínez J, de Miguel C. Effect of TNF-Alpha on Caveolin-1 Expression and Insulin Signaling During Adipocyte Differentiation and in Mature Adipocytes. Cell Physiol Biochem 2015;36:1499-1516.

21. Shi F, Zhao TZ, Wang YC, Cao XS, Yang CB, Gao Y, Li CF, Zhao JD, Zhang S, Sun XQ. The Impact of Simulated Weightlessness on Endothelium-Dependent Angiogenesis and the Role of Caveolae/Caveolin-1. Cell Physiol Biochem 2016;38:502-513.

22. Cordes N, Frick S, Brunner TB, Pilarsky C, Grutzmann R, Sipos B, Kloppel G, McKenna WG, Bernhard EJ: Human pancreatic tumor cells are sensitized to ionizing radiation by knockdown of caveolin-1. Oncogene 2007;26:6851-6862.

23. Rodel F, Capalbo G, Rodel C, Weiss C: Caveolin-1 as a prognostic marker for local control after preoperative chemoradiation therapy in rectal cancer. Int J Radiat Oncol Biol Phys 2009;73:846-852.

24. Quann K, Gonzales DM, Mercier I, Wang C, Sotgia F, Pestell RG, Lisanti MP, Jasmin JF: Caveolin-1 is a negative regulator of tumor growth in glioblastoma and modulates chemosensitivity to temozolomide. Cell Cycle 2013;12:1510-1520.

25. Sloan EK, Stanley KL, Anderson RL: Caveolin-1 inhibits breast cancer growth and metastasis. Oncogene 2004;23:7893-7897.

26. Basu Roy UK, Henkhaus RS, Loupakis F, Cremolini C, Gerner EW, Ignatenko NA: Caveolin-1 is a novel regulator of K-RAS-dependent migration in colon carcinogenesis. Int J Cancer 2013;133:43-57.

27. Pancotti F, Roncuzzi L, Maggiolini M, Gasperi-Campani A: Caveolin-1 silencing arrests the proliferation of metastatic lung cancer cells through the inhibition of STAT3 signaling. Cell Signal 2012;24:1390-1397.

28. Yang G, Goltsov AA, Ren C, Kurosaka S, Edamura K, Logothetis R, Demayo FJ, Troncoso P, Blando J, Digiovanni J, Thompson TC: Caveolin-1 upregulation contributes to c-Myc-induced high-grade prostatic intraepithelial neoplasia and prostate cancer. Mol Cancer Res 2012;10:218-229.

29. Tang W, Feng X, Zhang S, Ren Z, Liu Y, Yang B, lv B, Cai Y, Xia J, Ge N: Caveolin-1 Confers Resistance of Hepatoma Cells to Anoikis by Activating IGF-1 Pathway. Cell Physiol Biochem 2015;36:1223-1236.

30. Savage K, Lambros MB, Robertson D, Jones RL, Jones C, Mackay A, James M, Hornick JL, Pereira EM, Milanezi F, Fletcher CD, Schmitt FC, Ashworth A, Reis-Filho JS: Caveolin 1 is overexpressed and amplified in a subset of basal-like and metaplastic breast carcinomas: a morphologic, ultrastructural, immunohistochemical, and in situ hybridization analysis. Clin Cancer Res 2007;13:90-101.

31. Elsheikh SE, Green AR, Rakha EA, Samaka RM, Ammar AA, Powe D, Reis-Filho JS, Ellis IO: Caveolin 1 and Caveolin 2 are associated with breast cancer basal-like and triple-negative immunophenotype. Br J Cancer 2008;99:327-334.

32. Neve RM, Chin K, Fridlyand J, Yeh J, Baehner FL, Fevr T, Clark L, Bayani N, Coppe JP, Tong F, Speed T, Spellman PT, Devries S, Lapuk A, Wang NJ, Kuo WL, Stilwell JL, Pinkel D, Albertson DG, Waldman FM, Mccormick F, Dickson RB, Johnson MD, Lippman M, Ethier S, Gazdar A, Gray JW: A collection of breast cancer cell lines for the study of functionally distinct cancer subtypes. Cancer cell 2006;10:515-527. 


\section{Cellular Physiology Cell Physiol Biochem 2017;44:778-791

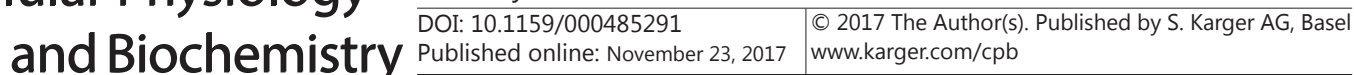 \\ Zou et al.: Knockdown of CAVEOLIN-1 Increases Radiosensitivity in TNBC Cells}

33. Gonzalez JE, Barquinero JF, Lee M, Garcia O, Casaco A: Radiosensitization induced by the anti-epidermal growth factor receptor monoclonal antibodies cetuximab and nimotuzumab in A431 cells. Cancer Biol Ther 2012;13:71-76.

34. Liccardi G, Hartley JA, Hochhauser D: EGFR nuclear translocation modulates DNA repair following cisplatin and ionizing radiation treatment. Cancer Res 2011;71:1103-1114.

-35. Djuzenova CS, Elsner I, Katzer A, Worschech E, Distel LV, Flentje M, Polat B: Radiosensitivity in breast cancer assessed by the histone gamma-H2AX and 53BP1 foci. Radiat Oncol 2013;8:98.

36. Pawlik TM, Keyomarsi K: Role of cell cycle in mediating sensitivity to radiotherapy. Int J Radiat Oncol Biol Phys 2004;59:928-942.

37. Burgermeister E, Liscovitch M, Rocken C, Schmid RM, Ebert MP: Caveats of caveolin-1 in cancer progression. Cancer Lett 2008;268:187-201.

38. Park SS, Kim JE, Kim YA, Kim YC, Kim SW: Caveolin-1 is down-regulated and inversely correlated with HER2 and EGFR expression status in invasive ductal carcinoma of the breast. Histopathology 2005;47:625-630.

39. Witkiewicz AK, Dasgupta A, Sammons S, Er O, Potoczek MB, Guiles F, Sotgia F, Brody JR, Mitchell EP, Lisanti MP: Loss of stromal caveolin-1 expression predicts poor clinical outcome in triple negative and basal-like breast cancers. Cancer Biol Ther 2010;10:135-143.

40. Dong Y, Li A, Wang J, Weber JD, Michel LS: Synthetic lethality through combined Notch-epidermal growth factor receptor pathway inhibition in basal-like breast cancer. Cancer Res 2010;70:5465-5474.

41. Carey LA, Rugo HS, Marcom PK, Mayer EL, Esteva FJ, Ma CX, Liu MC, Storniolo AM, Rimawi MF, ForeroTorres A, Wolff AC, Hobday TJ, Ivanova A, Chiu WK, Ferraro M, Burrows E, Bernard PS, Hoadley KA, Perou CM, Winer EP: TBCRC 001: randomized phase II study of cetuximab in combination with carboplatin in stage IV triple-negative breast cancer. J Clin Oncol 2012;30:2615-2623.

42. Raju U, Riesterer O, Wang ZQ, Molkentine DP, Molkentine JM, Johnson FM, Glisson B, Milas L, Ang KK: Dasatinib, a multi-kinase inhibitor increased radiation sensitivity by interfering with nuclear localization of epidermal growth factor receptor and by blocking DNA repair pathways. Radiother Oncol 2012;105:241249.

43. Gonzalez-Angulo AM, Timms KM, Liu S, Chen H, Litton JK, Potter J, Lanchbury JS, Stemke-Hale K, Hennessy BT, Arun BK, Hortobagyi GN, Do KA, Mills GB, Meric-Bernstam F: Incidence and outcome of BRCA mutations in unselected patients with triple receptor-negative breast cancer. Clin Cancer Res 2011;17:1082-1089.

44. Zajac M, Moneo MV, Carnero A, Benitez J, Martinez-Delgado B: Mitotic catastrophe cell death induced by heat shock protein 90 inhibitor in BRCA1-deficient breast cancer cell lines. Mol Cancer Ther 2008;7:23582366.

45. Drew Y, Mulligan EA, Vong WT, Thomas HD, Kahn S, Kyle S, Mukhopadhyay A, Los G, Hostomsky Z, Plummer ER, Edmondson RJ, Curtin NJ: Therapeutic potential of poly(ADP-ribose) polymerase inhibitor AG014699 in human cancers with mutated or methylated BRCA1 or BRCA2. J Natl Cancer Inst 2011;103:334-346.

46. Zhu H, Yue J, Pan Z, Wu H, Cheng Y, Lu H, Ren X, Yao M, Shen Z, Yang JM: Involvement of Caveolin-1 in repair of DNA damage through both homologous recombination and non-homologous end joining. PloS One 2010;5:e12055.

47. Kimple RJ, Smith MA, Blitzer GC, Torres AD, Martin JA, Yang RZ, Peet CR, Lorenz LD, Nickel KP, Klingelhutz AJ, Lambert PF, Harari PM: Enhanced radiation sensitivity in HPV-positive head and neck cancer. Cancer Res 2013;73:4791-4800.

48. Williams TM, Medina F, Badano I, Hazan RB, Hutchinson J, Muller WJ, Chopra NG, Scherer PE, Pestell RG, Lisanti MP: Caveolin-1 gene disruption promotes mammary tumorigenesis and dramatically enhances lung metastasis in vivo. Role of Cav-1 in cell invasiveness and matrix metalloproteinase (MMP-2/9) secretion. J Biol Chem 2004;279:51630-51646.

49. Sloan EK, Stanley KL, Anderson RL. Caveolin-1 inhibits breast cancer growth and metastasis. Oncogene 2004;23:7893-7897.

50. Bonuccelli G, Casimiro MC, Sotgia F, Wang C, Liu M, Katiyar S, Zhou J, Dew E, Capozza F, Daumer KM, Minetti C, Milliman JN, Alpy F, Rio MC, Tomasetto C, Mercier I, Flomenberg N, Frank PG, Pestell RG, Lisanti MP: Caveolin-1 (P132L), a common breast cancer mutation, confers mammary cell invasiveness and defines a novel stem cell/metastasis-associated gene signature. Am J Pathol 2009;174:1650-1662.

-51 Mineva ND, Wang X, Yang S, Ying H, Xiao ZX, Holick MF, Sonenshein GE: Inhibition of RelB by 1, 25-dihydroxyvitamin D3 promotes sensitivity of breast cancer cells to radiation. J Cell Physiol 2009;220:593-599. 